\title{
Tratamento de sementes com bioestimulante ao milho submetido a diferentes variabilidades na distribuição espacial das plantas
}

\author{
Seed treatment with biostimulant on maize submitted \\ to different plant spatial variability distribution
}

\author{
Daniel Fernando Kolling ${ }^{I^{*}}$ Luis Sangoi ${ }^{\mathrm{I}}$ Clovis Arruda de Souza ${ }^{\mathrm{I}}$ \\ Diego Eduardo Schenatto ${ }^{\mathrm{I}}$ Willian Giordani ${ }^{\mathrm{I}}$ Cristian Majolo Boniatti ${ }^{\mathrm{I}}$
}

\section{RESUMO}

A utilização de bioestimulantes pode auxiliar a mitigar os prejuízos ao milho, ocasionados pela má qualidade de estande. Este trabalho foi conduzido objetivando avaliar o efeito do tratamento de sementes com bioestimulante sobre o desempenho agronômico do milho, submetido a diferentes níveis de variabilidade na distribuição espacial das plantas na linha de semeadura. $O$ experimento foi implantado em Lages, SC, durante o ano agrícola de 2013/2014. O delineamento experimental foi de blocos ao acaso, dispostos em parcelas subdivididas. Nas parcelas principais, testaram-se três niveis de desuniformidade espacial na linha: 0, 50 e 100\% do Coeficiente de Variação (CV). No nível 0 $\%$ de $C V$, todas as sementes foram uniformemente distribuidas no sulco de semeadura, a uma distância de $17 \mathrm{~cm}$ entre si. Nos demais níveis de $C V$, as distâncias entre sementes variaram conforme o tratamento. Nas subparcelas, testou-se a presença ou ausência do tratamento de sementes com bioestimulante. $O$ aumento da variabilidade na distribuição espacial das plantas reduziu a área foliar e o teor de clorofila da folha índice no espigamento, bem como o diametro do colmo na colheita, independentemente do tratamento de sementes com bioestimulante. Isso contribuiu para reduzir o número de grãos por espiga e o rendimento de grãos dos tratamentos com 50 e $100 \%$ de CV na variabilidade espacial, tanto na presença quanto na ausência do bioestimulante. Portanto, o tratamento de sementes com bioestimulante não mitigou os prejuizos ao rendimento de grãos do milho ocasionados pela distribuição espacial irregular das plantas na linha de semeadura.

Palavras-chave: Zea mays, regulador de crescimento, qualidade de estande, emergência desuniforme.

\section{ABSTRACT}

The use of biostimulants may help to mitigate damages to maize caused by poor stand quality. This research was carried out aiming to evaluate the effect of seed treatment with biostimulant on the agronomic performance of maize submitted to different levels of plant spatial distribution at the sowing row. The experiment was set in Lages, SC, during the 2013/2014 growing season. A randomized block design disposed in split plots was used. Three levels of plant spatial unevenness at the sowing row were tested in the main plots: 0, 50 and $100 \%$ of the variation coefficient $(\mathrm{CV})$. At the level $0 \%$ of $C V$ all seeds were evenly distributed with a distance of $17 \mathrm{~cm}$ from each other. At the other levels of $\mathrm{CV}$, the distance between seeds varied according to the treatment. The presence or absence of seed treatment with biostimulant was assessed in the split plots. The increase in plant spatial distribution variability at the sowing row decreased leaf area and leaf chlorophyll content at silking, as well as stem diameter at harvest, regardless of seed treatment with biostimulant. Such behavior contributed to decrease the number of kernels per ear and grain yield of treatments with 50 and $100 \%$ C.V. of spatial variability, with and without biostimulant seed treatment. Therefore, seed treatment with biostimulant did not mitigate damages to maize grain yield caused by irregular spatial plant distribution at sowing row.

Key words: Zea mays, growth regulator, stand quality, uneven emergence.

\section{INTRODUÇÃO}

O milho é uma das espécies mais sensíveis à competição intraespecífica (SANGOI et al., 2012). A intensidade dessa competição depende de algumas práticas culturais importantes durante a semeadura, tais como a velocidade de deslocamento do trator e a profundidade de deposição das sementes, as quais interferem na homogeneidade da distribuição espacial e temporal das plantas na lavoura (LAUER \& RANKIN, 2004).

\footnotetext{
IDepartamento de Agronomia, Centro de Ciências Agroveterinárias, Universidade do Estado de Santa Catarina (UDESC), Av. Luiz de Camões, 2090, 88520-000, Lages, SC, Brasil. E-mail: dfkolling@gmail.com. *Autor para correspondência.
} 
A distribuição espacial irregular das sementes no sulco de semeadura promove o desenvolvimento de plantas com diferentes capacidades de captar recursos do ambiente, gerando o aparecimento de plantas dominantes e dominadas e aumentando a variabilidade na produção de grãos de cada indivíduo (MADDONNI \& OTEGUI, 2006).

Trabalhos conduzidos por NIELSEN (2001), ANDRADE \& ABBATE (2005), TOLLENAAR et al. (2006) e SANGOI et al. (2012) avaliaram os efeitos decorrentes da variação espacial na distribuição das plantas. Coletivamente, as observações realizadas nestes estudos demonstraram que houve menor aproveitamento da radiação solar, redução de área foliar, menor acúmulo de massa seca e produção de grãos por planta à medida que aumentou a variabilidade na distribuição espacial das plantas na linha. Os prejuízos oriundos da irregularidade na distribuição espacial dependem da sua intensidade, do nível de fertilidade do solo, das características fenotípicas do híbrido e do rendimento de grãos almejado (LUQUE et al. 2006; PAGANO \& MADDONNI, 2006).

Uma estratégia para minimizar os efeitos decorrentes de semeaduras desuniformes é a utilização de bioestimulantes (KLAHOLD et al., 2006). CASTRO \& VIEIRA(2001) definiram bioestimulante como uma mistura de reguladores de crescimento vegetal, ou de um ou mais reguladores vegetais com outros compostos de natureza bioquímica diferente (aminoácidos, nutrientes, vitaminas, etc). Esses produtos favorecem a expressão do potencial genético das plantas mediante alterações dos processos vitais e estruturais, promovendo um equilíbrio hormonal e estimulando o desenvolvimento do sistema radicular (CASTRO \& VIEIRA, 2001; SILVA et al., 2008).

Os reguladores de crescimento têm sido associados aos micronutrientes no tratamento de sementes, buscando-se estimular a germinação e melhorar estabelecimento das plantas a campo (SILVA et al., 2008). Esses produtos aumentam a capacidade de absorção de água e de nutrientes, bem como a resistência a estresses hídricos, permitindo o melhor desenvolvimento das plantas em condições subótimas (VASCONCELOS, 2006; CASTRO et al., 2008).

Apesar dessas vantagens, os resultados dos trabalhos de pesquisa com o tratamento de sementes com bioestimulantes são contraditórios. Entre os produtos mais usados no país com esta finalidade está o Stimulate ${ }^{\circledR}$. De acordo com DÁRIO \& BALTIERE (1998) e FERREIRA et al. (2007), a utilização de Stimulate não afetou a germinação e emergência de plântulas em sementes de milho. TWEDDELL et al.
(2000), utilizando o mesmo produto em plantas de milho submetidas a diferentes níveis de adubação nitrogenada, também não verificaram diferenças significativas na produção de grãos, biomassa seca e concentração de nutrientes no tecido foliar. Por outro lado, KLAHOLD et al. (2006) relataram que a utilização desse regulador de crescimento promoveu incrementos no rendimento de grãos da soja.

Os resultados contrastantes reportados na literatura quanto à utilização de bioestimulantes indicam que as repostas à aplicação desses produtos dependem da espécie da planta, da composição das substâncias húmicas presentes nos produtos e das condições do ambiente. Diante desse contexto, o presente trabalho objetivou avaliar o efeito do tratamento de sementes com bioestimulante sobre o desempenho agronômico do milho submetido a diferentes níveis de variabilidade espacial na distribuição das plantas no sulco de semeadura.

\section{MATERIAL E MÉTODOS}

O experimento foi conduzido em Lages, SC, durante o ano agrícola de 2013/2014. As coordenadas geográficas do local são $27^{\circ} 50^{\prime} 35^{\prime}$ de latitude Sul e 50 29 '45"de longitude Oeste, com altitude média de $849 \mathrm{~m}$. O solo da área experimental é classificado como Nitossolo Vermelho Distrófico típico. A análise de solo feita em setembro de 2013 apresentou as seguintes características: $56 \%$ de argila; $\mathrm{pH}$ em $\mathrm{H}_{2} \mathrm{O} 5,2$; índice SMP 5,7; 6,0\% de Matéria Orgânica; $4,5 \mathrm{mg} \mathrm{dm}^{-3}$ de $\mathrm{P} ; 183 \mathrm{mg} \mathrm{dm}^{-3}$ de $\mathrm{K} ; 5,69 \mathrm{cmolc} \mathrm{dm}^{-3}$ de Ca; 2,38cmolc $\mathrm{dm}^{-3} \mathrm{Mg}$; $0,2 \mathrm{cmolc} \mathrm{dm}^{-3} \mathrm{Al} ; 8,82 \mathrm{cmolc} \mathrm{dm}^{-3}$ de CTC.

$\mathrm{O}$ delineamento experimental utilizado foi de blocos ao acaso dispostos em parcelas subdivididas, com três repetições. As parcelas principais foram constituídas por três níveis de desuniformidade espacial na linha de cultivo, equivalentes a 0,50 e $100 \%$ do coeficiente de variação (C.V.). No nível $0 \%$ de $\mathrm{CV}$, as sementes foram uniformemente distribuídas nos sulcos de semeadura na distância de $17 \mathrm{~cm}$ entre si. As distâncias entre sementes nos demais tratamentos com variabilidade espacial foram calculadas através do software Minitab, utilizandose a função randomização de dados com distribuição normal. Nesta função, foram informadas a média, o desvio padrão e o número de dados (plantas por linha) em cada tratamento. Para cada percentagem de coeficiente de variação, o software gerou aleatoriamente a posição das plantas nos sulcos de plantio. Em função dessas distâncias, marcaram-se 
barbantes para que as sementes fossem colocadas na posição desejada em cada tratamento.

Nas subparcelas, foram alocados os tratamentos com presença e ausência de bioestimulante. Utilizou-se o produto comercial Stimulate $^{\circledR}$, que é composto por $0,009 \%$ de cinetina (citocinina), 0,005\% de ácido giberélico (giberelina) e $0,005 \%$ de ácido indolbutírico (auxina). O produto foi misturado homogeneamente às sementes no dia da semeadura, na dose de $15 \mathrm{ml} \mathrm{kg}^{-1}$ de semente.

A semeadura do ensaio ocorreu no dia 19 de outubro de 2013 com semeadoras manuais diretamente sobre uma cobertura morta de aveia branca. Aplicaram-se, no dia da semeadura, $30 \mathrm{~kg}$ ha $^{-1}$ de $\mathrm{N}, 295 \mathrm{~kg} \mathrm{ha}^{-1}$ de $\mathrm{P}_{2} \mathrm{O}_{5}$ e $170 \mathrm{~kg} \mathrm{ha}^{-1}$ de $\mathrm{K}_{2} \mathrm{O}$, seguindo as recomendações da Comissão de Química e Fertilidade do Solo - RS/SC (2004) para alcançar produtividades de $18.000 \mathrm{~kg} \mathrm{ha}^{-1}$. Para a adubação de cobertura, foram utilizados $250 \mathrm{~kg} \mathrm{ha}^{-1}$ de $\mathrm{N}$ parcelados igualmente nos estádios V4, V8 e V12 da escala proposta por RITCHIE et al. (1993). Quando as plantas estavam no estádio V3, foi realizado o desbaste para alcançar um estande final de 80.000 plantas ha ${ }^{-1}$. O híbrido utilizado foi o P30R50YH e o espaçamento entre linhas de $0,7 \mathrm{~m}$.

No dia da semeadura, efetuou-se o controle preventivo de plantas daninhas com aplicação em pré-emergência dos herbicidas Atrazina + Simazina, nas doses de 1,5+1,15kg i.a. ha-1. Quando as plantas se encontravam em V4, complementou-se o controle das plantas daninhas com a aplicação do herbicida Tembotriona, na dose de $100 \mathrm{~g}$ i.a. ha ${ }^{-1}$. Além disso, foi realizada uma aplicação dos fungicidas Azixistrobina + Ciproconazol, nas doses de $60+25 \mathrm{~g}$ i.a. ha ${ }^{-1}$, quando o milho estava nos estádios V12 e V18, para o controle preventivo de doenças.

Cada subparcela foi composta por quatro linhas de $6 \mathrm{~m}$ de comprimento, espaçadas de $70 \mathrm{~cm}$ entre si. Todas as avaliações foram feitas nas duas fileiras centrais, excluindo $0,5 \mathrm{~m}$ na extremidade de cada linha, perfazendo uma área útil de $7 \mathrm{~m}^{2}$.

Numa das linhas centrais das subparcelas, foram identificadas seis plantas em sequência, para realizar a avaliação de área foliar no momento em que as plantas atingiram o estádio R1 (espigamento). A área foliar foi obtida medindo-se o comprimento (C) e a maior largura $(\mathrm{L})$ de todas as folhas verdes. A área foliar por planta foi estimada utilizando-se a fórmula: $\mathrm{A}=\mathrm{CxLx} 0,75$, onde o valor 0,75 é um coeficiente de correção, uma vez que as folhas não apresentam área retangular. Utilizou-se a folha inserida no nó em que a planta produziu a espiga superior (folha índice) para avaliação do teor de clorofila. Essa avaliação também foi feita em R1, utilizando-se o clorofilômetro, modelo Spad 502. As plantas marcadas também foram utilizadas para avaliar o diâmetro de colmo na colheita.

A colheita do ensaio foi realizada no dia 23 de abril de 2014, quando a umidade dos grãos situavase entre de $18 \%$ e $24 \%$. As espigas foram colhidas, trilhadas e os grãos secos em estufa até a obtenção de massa constante a $65^{\circ} \mathrm{C}$. Os grãos foram pesados, os valores obtidos convertidos para umidade padrão de $13 \%$, a qual foi utilizada para a determinação do rendimento de grãos e dos componentes do rendimento (número de grãos por espiga e massa de 1.000 grãos).

Os dados obtidos foram submetidos à análise de variância utilizando-se o teste F. Os valores de $\mathrm{F}$ foram considerados significativos ao nível de significância de 5\% $(\mathrm{P}<0,05)$. Quando alcançada significância estatística, as médias de cada tratamento foram comparadas utilizando-se análise de regressão polinomial ao nível de significância de 5\%.

\section{RESULTADOS E DISCUSSÃO}

O rendimento de grãos registrado no ensaio variou de 13.132 a $15.055 \mathrm{~kg} \mathrm{ha}^{-1}$. Ele foi afetado pelo efeito principal da variabilidade espacial da distribuição de plantas (Tabela 1). Conforme aumentou o coeficiente de variação da distribuição de plantas na linha de semeadura, houve redução do rendimento de grãos, independente da presença ou ausência do bioestimulante (Figura 1A). Para cada $10 \%$ de incremento no $\mathrm{CV}$, houve um decréscimo na produtividade de 187 e $65 \mathrm{~kg} \mathrm{ha}^{-1}$, com e sem o tratamento de sementes com bioestimulante, respectivamente.

A diminuição na produtividade esteve associada à redução no número de grãos por espiga (Figura 1B). Conforme aumentou a irregularidade da distribuição das plantas no sulco de semeadura, as espigas produziram menos grãos. Isso comprometeu o potencial produtivo da cultura, pois se acentuou a competição intraespecífica, devido ao subaproveitamento dos recursos do ambiente, conforme já reportado por ANDRADE \& ABBATE (2005), TOLLENAAR et al. (2006) e SANGOI et al. (2012). Tanto nas parcelas tratadas quanto nas não tratadas com Stimulate ${ }^{\circledR}$, houve um decréscimo de aproximadamente 32 grãos por espiga no tratamento com $100 \%$ de C.V., em relação às parcelas onde as sementes foram uniformemente distribuídas.

O componente de rendimento massa de mil grãos apresentou um comportamento estável, com redução de aproximadamente 1 grama para cada $25 \%$ de aumento no coeficiente de variação, tanto na presença quanto na ausência do bioestimulante (Figura 1C).

Ciência Rural, v.46, n.2, fev, 2016. 
Tabela 1 - Valores de F calculados pela análise de variância e coeficientes de variação das parcelas e subparcelas para as características agronômicas avaliadas no experimento.

\begin{tabular}{|c|c|c|c|c|c|}
\hline Característica Avaliada & Distribuição de Plantas & Bioestimulante & $\mathrm{D} \times \mathrm{B}$ & CV (\%) Parcela & CV (\%) SubParcela \\
\hline Rendimento de grãos & $3,81^{*}$ & $2,11^{\mathrm{ns}}$ & $0,85^{\text {ns }}$ & 6,55 & 5,66 \\
\hline Grãos por espiga & $3,02^{*}$ & $0,09^{\mathrm{ns}}$ & $0,03^{\text {ns }}$ & 6,29 & 5,31 \\
\hline Massa de 1000 grãos & $0,53^{\mathrm{ns}}$ & $0,15^{\mathrm{ns}}$ & $1,57^{\mathrm{ns}}$ & 1,95 & 1,38 \\
\hline Área foliar & $9,05^{*}$ & $2,28^{\text {ns }}$ & $0,72^{\text {ns }}$ & 6,75 & 7,74 \\
\hline Teor de Clorofila & $10,90^{*}$ & $0,21^{\mathrm{ns}}$ & $1,58^{\mathrm{ns}}$ & 3,05 & 2,07 \\
\hline Diâmetro de colmo & $22,85^{* *}$ & $2,40^{\mathrm{ns}}$ & $1,38^{\text {ns }}$ & 3,40 & 2,38 \\
\hline
\end{tabular}

${ }^{\text {ns }}$ não significativo; ${ }^{*}$ ignificativo a $5 \%$ de probabilidade de erro; ${ }^{* *}$ significativo a $1 \%$ de probabilidade de erro.
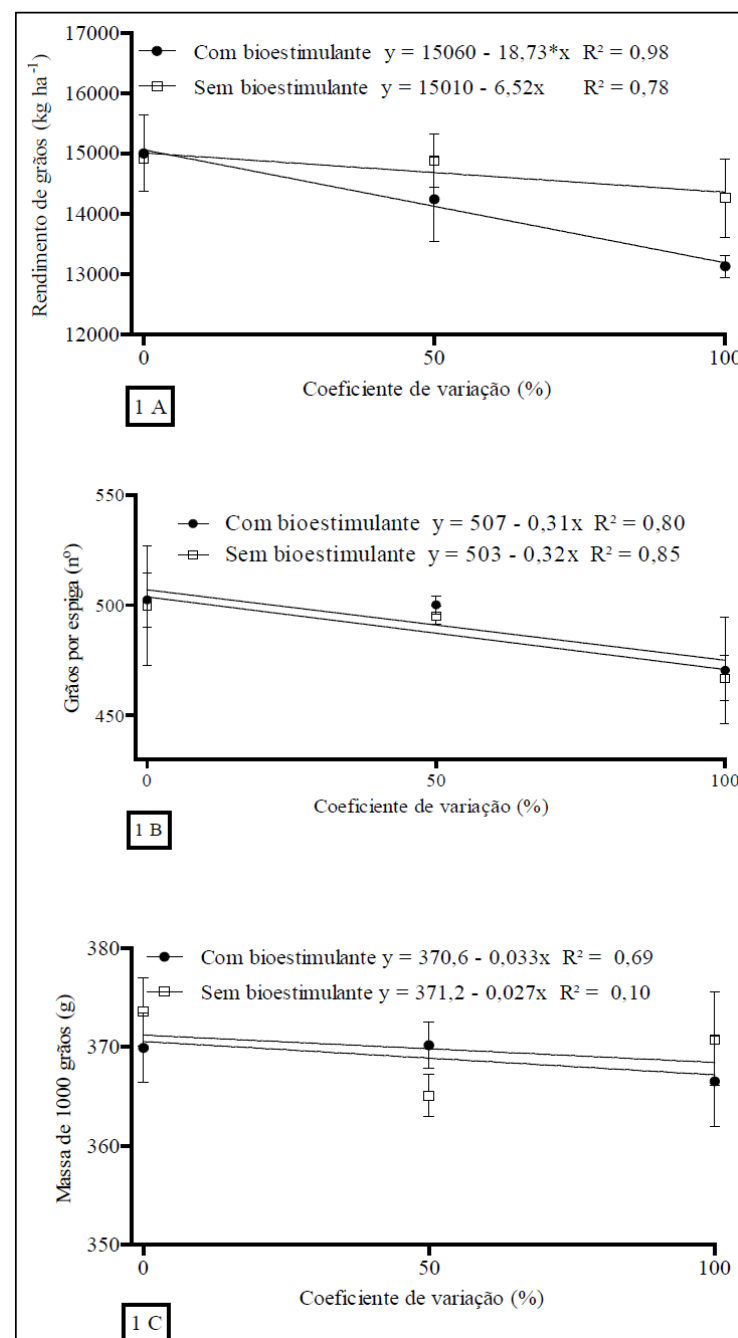

Figura 1 - Rendimento de grãos (1A), número de grãos por espiga (1B) e massa de 1000 grãos (1C), em função do coeficiente de variação na distribuição espacial das plantas na linha de semeadura e do tratamento de sementes com bioestimulante. Lages, SC, $2013 / 2014$.
À medida que aumentou a variabilidade na distribuição espacial das plantas, houve redução da área foliar no espigamento (Figura 2A) do teor de clorofila da folha índice (Figura 2B) e do diâmetro do colmo na colheita (Figura 2C), independentemente do tratamento das sementes com bioestimulante. Os maiores valores de área foliar e teor de clorofila da folha, índice registrados quando as plantas estavam uniformemente distribuídas na linha, possivelmente contribuíram para fomentar a sua atividade fotossintética durante a floração e início do enchimento de grãos. Isso possibilitou a fixação de um maior número de grãos por espiga (Figura 1B), o que se traduziu em maior rendimento de grãos (Figura 1A).

Este trabalho foi conduzido com base na hipótese de que o tratamento de sementes de milho com bioestimulante poderia mitigar os efeitos negativos da irregularidade na distribuição espacial das plantas na linha de semeadura sobre o rendimento de grãos. Os resultados obtidos não confirmaram esta hipótese, pois não houve efeito significativo do produto testado sobre nenhuma das variáveis avaliadas (Tabela 1) e o rendimento decresceu com o aumento na variabilidade espacial, tanto na presença quanto na ausência do tratamento de sementes com bioestimulante (Figura 1A). FERREIRA et al. (2007) também não detectaram diferenças significativas na produtividade do milho em função da aplicação de bioestimulante na semente de milho.

A ausência de efeito mitigador do Stimulate sobre o estresse ocasionado ao milho pela variabilidade espacial na distribuição das plantas pode estar relacionada à composição do bioestimulante usado no trabalho. As citocininas atuam estimulando a divisão celular em tecidos supridos com um nível adequado de auxinas. Tanto a auxina como a citocinina participam na regulação 


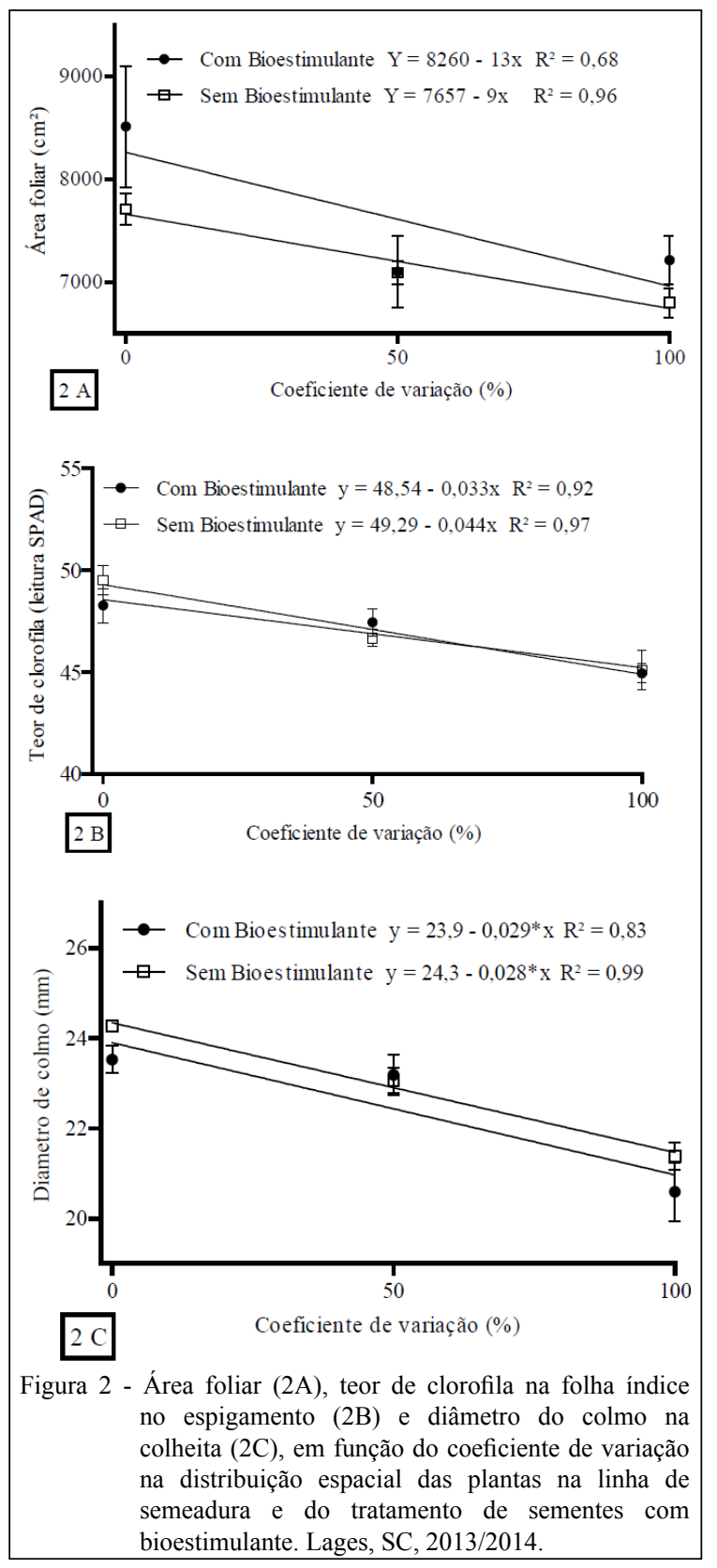

do ciclo celular, controlando a atividade de quinases dependentes de ciclina. Todavia, apesar de a auxina atuar em sinergismo com a citocinina para estimular a divisão celular, essas classes hormonais atuam antagonicamente no controle da iniciação de ramos (promovido por citocininas) e de raízes (promovido por auxinas), bem como no estabelecimento da dominância apical (SALISBURY \& ROSS, 2012). Também há um efeito antagônico de citocinina sobre giberelina em células que estão em ativo processo de alongação celular por ação de giberelina ativa.
Nesses casos, a aplicação exógena de citocinina promove a queda acentuada nos níveis de giberelina ativa. Por este motivo, agronomicamente são utilizadas citocininas como substâncias "redutoras" ou "retardantes" de crescimento vegetal, sendo efetivas na redução da altura de plantas de algodão e trigo (RADEMACHER, 2000). A concentração de giberelina é igual à de citocinina no produto Stimulate $^{\circledR}$. Portanto, é possível que um fitohormônio tenha inibido a ação do outro.

Este comportamento diferiu do registrado em trabalhos conduzidos por CASTRO \& VIEIRA (2001) com a cultura do feijão e de ALMEIDA et al. (2004) com a soja, que observaram um desempenho superior das plantas submetidas ao tratamento de sementes com bioestimulante em relação à produção final.

Os dados obtidos no presente estudo corroboram as ponderações expostas por KARNOK (2000), salientando que, quando as plantas são cultivadas num ambiente favorável ao desenvolvimento, é mais difícil identificar os efeitos favoráveis dos bioestimulantes. Contudo, quando submetidas a condições de estresse, as plantas tratadas com estes produtos mostram um desempenho superior, pois desenvolvem um sistema de defesa, devido ao incremento do nível de antioxidantes. Deve-se destacar que a área experimental em que se desenvolveu o trabalho possui elevados índices de fertilidade e de matéria orgânica, decorrentes da adoção de um sistema de plantio direto consolidado há 15 anos. Além disso, foram utilizadas no ensaio práticas de manejo favoráveis à obtenção de altas produtividades, as quais redundaram em rendimentos de grãos superiores a $13.000 \mathrm{~kg} \mathrm{ha}^{-1}$ em todos os tratamentos (Figura 1A). Essa combinação de fatores pode ter mitigado o efeito positivo do bioestimulante sobre o desempenho agronômico do milho.

A adoção de alto nível tecnológico de manejo na cultura atenua os efeitos do bioestimulante sobre o desenvolvimento do milho, mas não elimina a competição intraespecífica advinda da distribuição irregular das plantas na linha de semeadura. Portanto, mais importante do que tratar as sementes com reguladores de crescimento como o Stimulate ${ }^{\circledR}$ é realizar a operação de semeadura com esmero para que as sementes sejam uniformemente distribuídas e a produtividade da lavoura não seja comprometida.

\section{CONCLUSÃO}

A irregularidade na distribuição espacial das plantas na linha de semeadura reduz o rendimento de grãos do milho e, o tratamento de sementes com 
bioestimulante não mitiga os prejuízos ao rendimento de grãos do milho ocasionados pela distribuição espacial irregular das plantas na linha de semeadura.

\section{AGRADECIMENTOS}

A Coordenação de Aperfeiçoamento de Pessoal de Nível Superior (CAPES), pela bolsa de doutorado concedida ao primeiro autor. Ao Conselho Nacional de Desenvolvimento Científico e Tecnológico $(\mathrm{CNPq})$ pelo financiamento através do Edital Universal 014/2014.

\section{REFERÊNCIAS}

ALMEIDA, J.C.V. Stimulate ${ }^{\circledR}$ como regulador de crescimento na cultura da soja. In: CONGRESSO BRASILEIRO D SOJA, 3., 2004, Foz do Iguaçu, PR. Anais... Londrina: Embrapa Soja, 2004. p.34.

ANDRADE, F.H.; ABBATE, P.E. Response of maize and soybean to variability in stand uniformity. Agronomy Journal, v.97, p.1263-1269, 2005. Disponível em: <http://dx.doi.org/10.2134/ agronj2005.0006>. Acesso em: 16 mar. 2015. doi: 10.2134/ agronj2005.0006

CASTRO, G.S.A. et al. Tratamento de sementes de soja com inseticidas e um bioestimulante. Pesquisa Agropecuária Brasileira, v.43, p.1311-1318, 2008. Disponível em: <http:// dx.doi.org/10.1590/S0100-204X2008001000008>. Acesso em: 12 mar. 2015. doi: 10.1590/S0100-204X2008001000008.

CASTRO, P.R.C.; VIEIRA, E.L. Aplicações de reguladores vegetais na agricultura tropical. Guaíba: Agropecuária, 2001. 132p.

COMISSÃO SUL-BRASILEIRADEQUÍMICAEFERTILIDADE DO SOLO - RS/SC. Manual de adubação e calagem para os estados do Rio Grande do Sul e Santa Catarina. 10.ed. Porto Alegre, 2004. 400p.

DÁRIO, G.J.A.; BALTIERI, E.M. Avaliação da eficiência do regulador vegetal Stimulate (citocinina + ácido indolbutírico + ácido giberélico) na cultura do milho (Zea mays L.). Piracicaba: ESALQ/USP, 1998. 12p. (Boletim Técnico).

FERREIRA, L.A. et al. Bioestimulante e fertilizante associados ao tratamento de sementes de milho. Revista Brasileira de Sementes, v.29, n.2, p.80-89, 2007. Disponível em: <http://dx.doi. org/10.1590/S0101-31222007000200011>. Acesso em: 20 fev. 2015. doi: 10.1590/S0101-31222007000200011.

KARNOK, K.J. Promises, promises: can biostimulants deliver? Golf Course Management, v.68, p.67-71, 2000. Online. Disponível em: <http://www.ipni.net/ipniweb/portal. nsf/0/94cfd5a0ed0843028525781 c0065437e/\$FILE/03\%20NA. Karnock.Golf\%20Course\%20Management $\% 20$ promises $\% 20$ promises \%20biostimulants\%202000.pdf $>$. Acesso em: 14 mar. 2015.

KLAHOLD, C.A. et al. Resposta da soja (Glycine max (L.) Merrill) à ação de bioestimulante. Acta Scientiarum Agronomy, v.28, n.2, p.179-185, 2006. Disponível em: <http://dx.doi. org/10.4025/actasciagron.v28i2.1032>. Acesso em: 22 mar. 2015. doi: 10.4025 /actasciagron.v28i2.1032.

LAUER, J.; RANKIN, M. Corn response to within row plant spacing variation. Agronomy Journal, v.96, n.6, p.1464-1468, 2004.
Disponível em: <http://dx.doi.org/10.2134/agronj2004.1464>. Acesso em: 02 abr. 2015. doi: 10.2134/agronj2004.1464.

LUQUE, S.F. et al. Genetic gains in grain yield and related physiological attributes in Argentine maize hybrids. Field Crops Research, v.93, p.383-397, 2006. Disponível em: $<$ http:// dx.doi.org/10.1016/j.fcr.2005.04.007>. Acesso em: 01 abr. 2015. doi:10.1016/j.fcr.2005.04.007.

MADDONNI, G.A.; OTEGUI, M.E. Intra-specific competition in maize: contribution of extreme plant hierarchies to grain yield, grain yield components and kernel composition. Field Crops Research, n.97 p.155-166, 2006. Disponível em: $<$ http://dx.doi. org/10.1016/j.fcr.2005.09.013>. Acesso em 02 abr. 2015. doi: 10.1016/j.fcr.2005.09.013.

NIELSEN, R.L. Stand establishment variability in corn. Department of Agronomy, Purdue University, 2001. Online. Disponível em: <http://www.agry.purdue.edu/ext/pubs/AGRY-9101_v5.pdf>. Acesso em: 21 jan. 2015.

PAGANO, E.; MADDONNI, G.A. Intra-specific competition in maize: early established hierarchies differ in plant growth and biomass partitioning to the ear around silking. Field Crops Research, v.101, p.306-320, 2006. Disponível em: <http://dx.doi. org/10.1016/j.fcr.2006.12.007>. Acesso em: 01 abr. 2015. doi: 10.1016/j.fcr.2006.12.007.

RADEMACHER, W. Growth retardants: effects on gibberellin biosynthesis and other metabolic pathways. Annual Review of Plant Physiology and Plant Molecular Biology, v.51, p.501531, 2000. Disponível em: <http://dx.doi.org/10.1146/annurev. arplant.51.1.501>. Acesso em: 25 jun. 2015. doi: 10.1146/ annurev.arplant.51.1.501.

RITCHIE, S.W. et al. How a corn plant develops. Ames: Iowa State University of Science and Technology, 1993. 26p.

SALISBURI, F.B.; ROSS, C.W. Fisiologia das plantas. 4.ed. (tradução de SANTAROSA, P.L.). São Paulo: Cengage Learning, 2012. 774p.

SANGOI, L. et al. Variabilidade na distribuição especial de plantas na linha e rendimento de grãos de milho. Revista Brasileira de Milho e Sorgo, v.11, p.268-277, 2012.

SILVA, T.T.A. et al. Qualidade fisiológica de sementes de milho na presença de bioestimulantes. Ciência Agrotecnologia, v.32, n.3 p.840-846, 2008. Disponível em: <http://dx.doi.org/10.1590/ S1413-70542008000300021>. Acesso em: 03 fev. 2015. doi: 10.1590/S1413-70542008000300021.

TOLLENAAR, M. et al. Effect of crowding stress on dry matter accumulation and harvest index. Agronomy Journal, v.98, p.930-937, 2006. Disponível em $<\mathrm{http} / / / d x . d o i . o r g / 10.2134$ /agronj2005.0336>. Acesso em: 16 mar. 2015. doi: 10.2134/agronj2005.0336.

TWEDDELL, R.J. et al. A two-year field study of a commercial biostimulant applied on maize as seed coating. Canadian Journal of Plant Science, v.80, n.4, p.805-87, 2000. Disponível em: $<$ http://dx.doi.org/10.4141/P99-142>. Acesso em: 21 fev. 2015. doi: 10.4141/P99-142.

VASCONCELOS, A.C.F. Uso de bioestimulantes nas culturas de milho e soja. 2006. 112f. Tese (Doutorado em Solos e Nutrição de Plantas) - Curso de Pós-graduação em agronomia. Escola Superior de Agricultura Luíz de Queiroz, Universidade de São Paulo, SP. 